2. Luo, D. \& Saltzman, M. T. Nature Biotechnol. 18, 33-37 (2000). 3. Bildirici, L. et al. Nature 405, 298 (2000)

4. Knoblauch, M. et al. Nature Biotechnol. 17, 906-909 (1999).

5. Tao, W. et al. Proc. Natl Acad. Sci. USA 84, 4180-4184 (1987).

6. König, K. J. Microsc. 200, 83-104 (2000).

7. Lippincott-Schwartz, J. et al. Nature Rev. Mol. Cell Biol. 2, 444-456 (2001).

8. Squirrell, J. M. et al. Nature Biotechnol. 17, 763-767 (1999)

9. So, P. T. C. et al. Bioimaging 3, 1-15 (1995).

10. Pepperkok, R. et al. Curr. Biol. 9, 269-272 (1999).

Competing financial interests: declared none.

Neurodegenerative disease

\section{Amyloid pores from pathogenic mutations}

A lzheimer's and Parkinson's diseases are associated with the formation in the brain of amyloid fibrils from $\beta$-amyloid and $\alpha$-synuclein proteins, respectively. It is likely that oligomeric fibrillization intermediates (protofibrils), rather than the fibrils themselves, are pathogenic, but the mechanism by which they cause neuronal death remains a mystery. We show here that mutant amyloid proteins associated with familial Alzheimer's and Parkinson's diseases form morphologically indistinguishable annular protofibrils that resemble a class of pore-forming bacterial toxins, suggesting that inappropriate membrane permeabilization might be the cause of cell dysfunction and even cell death in amyloid diseases.

The possibility that a molecular species other than the amyloid fibril could be pathogenic arose when oligomeric species rich in $\beta$-sheet structure (protofibrils) were found to be discrete intermediates in the fibrillization of $\beta$-amyloid $(A \beta)$ and of $\alpha$-synuclein in vitro ${ }^{1,2}$. An intermediate protofibril might therefore be pathogenic and be 'detoxified' by conversion to a fibril, as suggested by three general observations: there is no correlation between the quantity of fibrillar deposits at autopsy and the clinical severity of Alzheimer's or Parkinson's disease; transgenic mouse models of these conditions have disease-like phenotypes before fibrillar deposits can be detected ${ }^{1,2}$; and non-fibrillar $A \beta$ oligomers are toxic in cell culture ${ }^{3,4}$ and have activity in vivo ${ }^{5}$.

Toxic protofibrils have been implicated in other neurodegenerative diseases as well as in systemic amyloidoses such as type II diabetes (in which the amyloid protein is IAPP $)^{6}$ and familial amyloidotic polyneuropathy (in which it is transthyretin) ${ }^{7}$. Strikingly, protofibrils comprising proteins that are not associated with any disease are also toxic, suggesting that toxicity might arise from a shared structural feature of these intermediates ${ }^{8}$.

The pathogenic-protofibril hypothesis is supported by biophysical studies of variants of $A \beta$ and $\alpha$-synuclein linked to autosomaldominant forms of Alzheimer's and Parkin- son's diseases, respectively. The 'Arctic' mutation in amyloid-precursor protein, unlike all other mutations associated with Alzheimer's disease, reduces the total concentration of circulating $A \beta$, but mutant $A \beta_{A R C}$ forms protofibrils in vitro more rapidly and to a greater extent than the wild-type form? ${ }^{9}$.

The A30P and A53T $\alpha$-synuclein mutations associated with Parkinson's disease (in which an alanine residue is replaced by phenylalanine at position 30 or by threonine at position 53, respectively) both promote protofibril formation in vitro relative to wild-type $\alpha$-synuclein ${ }^{2}$. We examined the structural properties of $\mathrm{A} 30 \mathrm{P}, \mathrm{A} 53 \mathrm{~T}$ and $A \beta_{\text {ARC }}$ protofibrils for shared structural features that might be related to their toxicity.

Heterogeneous populations of A30P, $A 53 T$ and $A \beta_{A R C}$ protofibrils were fractionated by gel-filtration chromatography (H.A.L. et al., unpublished results). The fraction with the smallest A30P and A53T protofibrils contained $\beta$-sheet-rich (as measured by circular dichroism) oligomers comprising 20-25 $\alpha$-synuclein molecules (relative molecular mass, $320 \mathrm{~K}-380 \mathrm{~K}$; 22-26 monomers; H.A.L. et al., unpublished results). Analysis of this fraction by electron microscopy revealed annular species (diameter 8-12 nm; inner diameter 2.0-2.5 nm) and coiled species, both of which seemed to be related to the spherical and chain-like species reported earlier ${ }^{2}$. Protofibrillar $A \beta_{A R C}$, fractionated by a similar method, contained many annular species of similar appearance (Fig. 1), diameter $(7-10 \mathrm{~nm}$; inner diameter $1.5-2.0 \mathrm{~nm})$ and relative molecular mass $(150 \mathrm{~K}-250 \mathrm{~K}$, $40-60 \mathrm{~A} \beta_{\mathrm{ARC}}$ molecules).

The pore-like morphology of a subpopulation of amyloid protofibrils might explain the pore activity of $\alpha$-synuclein protofibrils in vesicle-permeabilization models ${ }^{10}$ and the

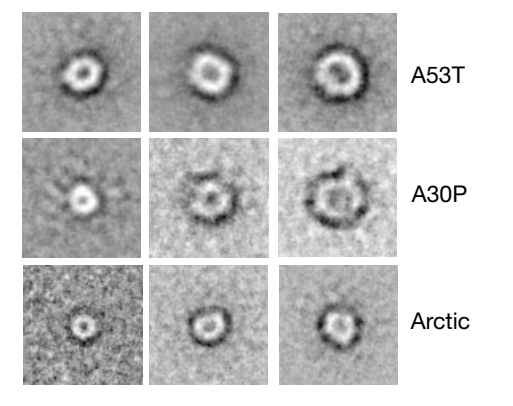

Figure 1 Mutations that cause Alzheimer's and Parkinson's diseases promote the formation of amyloid pores. Projection averages of annular protofibrils formed by the Parkinson's-diseaselinked $\alpha$-synuclein mutants $\mathrm{A} 53 \mathrm{~T}$ and $\mathrm{A} 30 \mathrm{P}$ and by the Alzheimer's-disease-linked $A \beta(1-40)_{A B C}$ 'Arctic' mutant (E22G). The images were calculated from a total of about 5,000-6,000 particles, which were obtained from 25-31 digitized electron micrographs of purified (by gel filtration on Superdex-200 $(\alpha$-synuclein) or Superose-6 (A $\beta))$ protofibrillar fractions corresponding to the lowest $-M_{\mathrm{r}}$ fraction of each mutant. Each panel shows an original area of $30.5 \times 30.5 \mathrm{~nm}$. channel-like properties of $A \beta$ (ref. 11). Other amyloid proteins, including huntingtin (in Huntington's disease $)^{12}$ and IAPP $^{6,12}$, also have pore-like activity in vitro. The small annular $A \beta$ and $\alpha$-synuclein protofibrils (Fig. 1) resemble the cytolytic $\beta$-barrel pore-forming toxins from bacteria such as Clostridium perfringens ${ }^{13}$.

As expected, amyloid pores are formed much less efficiently than bacterial pores, which during the course of evolution have optimized their ability to puncture host membranes. However, amyloid pores might be wholly or partly responsible for the cytotoxicity associated with the formation of amyloid fibrils in Alzheimer's and Parkinson's diseases and in other age-associated degenerative amyloid diseases.

Hilal A. Lashuel*, Dean Hartley*,

Benjamin M. Petre†, Thomas Walz†, Peter T. Lansbury Jr*

${ }^{*}$ Center for Neurologic Diseases, Brigham and Women's Hospital and Department of Neurology, Harvard Medical School, 65 Landsdowne Street, Cambridge, Massachusetts 02139, USA e-mail: plansbury@rics.bwh.harvard.edu $\uparrow$ Department of Cell Biology,

Harvard Medical School, 240 Longwood Avenue, Boston, Massachusetts 02115, USA

Lansbury, P. T. Proc. Natl Acad. Sci. USA 96, 3342-3344 (1999).

2. Goldberg, M. S. \& Lansbury, P. T. Nature Cell Biol. 2, E115-E119 (2000).

3. Hartley, D. M. et al. J. Neurosci. 19, 8876-8884 (1999).

4. Lambert, M. P. et al. Proc. Natl Acad. Sci. USA 95, 6448-6453 (1998).

5. Walsh, D. M. et al. Nature 416, 535-539 (2002).

6. Janson, J. et al. Diabetes 48, 491-498 (1999)

7. Sousa, M. M. et al. Am. J. Pathol. 159, 1993-2000 (2001).

8. Bucciantini, M. et al. Nature 416, 507-511 (2002).

9. Nilsberth, C. et al. Nature Neurosci. 4, 887-893 (2001)

10. Volles, M. J. \& Lansbury, P. T. Biochemistry 41, 4595-4602 (2002).

11. Lin, H., Bhatia, R. \& Lal, R. FASEB J. 15, 2433-2444 (2001). 12. Kagan, B. L., Hirakura, Y., Azimov, R. \& Azimova, R. Brain Res. Bull. 56, 281-284 (2001)

13. Hotze, E. M. et al. J. Biol. Chem. 277, 11597-11605 (2002) Competing financial interests: declared none.

COMMUNICATIONS ARISING Climate change

\section{Recent temperature trends in the Antarctic}

$\mathrm{t}$ is important to understand how temperatures across the Antarctic have changed in recent decades because of the huge amount of fresh water locked into the ice sheet and the impact that temperature changes may have on the ice volume. Doran et al. ${ }^{1}$ claim that there has been a net cooling of the entire continent between 1966 and 2000, particularly during summer and autumn. We argue that this result has arisen because of an inappropriate extrapolation of station data across large, data-sparse areas of the Antarctic.

The Antarctic-wide analysis made use of the University of East Anglia HadCRUT 
temperature data set, which provides monthly temperature anomalies (with respect to 1961-90) for $5^{\circ} \times 5^{\circ}$ grid boxes based on land and ship reports ${ }^{2}$. A spatially weighted average of the HadCRUT grid boxes that have data from 1958 to 2000 gives a warming of $0.176{ }^{\circ} \mathrm{C}$ per decade, which is significant at the $95 \%$ level.

Doran et al. calculated spatially smoothed trends using a technique that allowed grid boxes (there are only 16 of these south of $65^{\circ} \mathrm{S}$ ) to have a radius of influence of roughly $25 \%$ of the maximum width of the image, which we believe is too large, considering the highly localized nature of the factors that influence the climate at many of the stations. We suggest that the interpolation has given too much weight to grid boxes in data-sparse regions, resulting in a misleading representation of cooling over the continent, which is not supported by in situ or remote-sensing data.

Doran and colleagues' Fig. 2 shows annual and seasonal temperature trends for 1966-2000, with the largest cooling occurring in autumn over an area from the southern Weddell Sea to the South Pole. There is also pronounced cooling in spring and in annual trends. However, their Fig. 2 does not show the marked warming on the western side of the Antarctic Peninsula, which is greatest during winter ${ }^{3}$. It is unclear why the authors chose 1966-2000 for their analysis, as most of the temperature series in the HadCRUT data set begin in the late 1950s.

Although the spacing of stations around the coast is reasonable in the eastern hemisphere, there are large gaps in the data for the coast of west Antarctica, and only two stations in the interior have long records: those at the South Pole and Vostok $\left(78.5^{\circ} \mathrm{S}\right.$, $\left.106.9^{\circ} \mathrm{E}\right)$. The area in which Doran et al. report the greatest cooling is devoid of stations with long records, and HadCRUT includes no data for this region.

The warming on the western side of the Antarctic Peninsula is of limited spatial extent and is greatest close to Faraday Station $\left(65.3^{\circ} \mathrm{S}, 64.3^{\circ} \mathrm{W}\right)$, where the trend for $1951-2000$ is an increase of $1.09^{\circ} \mathrm{C}$ per decade during winter and $0.56{ }^{\circ} \mathrm{C}$ per decade annually (both values are significant at the 95\% level). However, at Halley Station $\left(75.5^{\circ} \mathrm{S}, 26.4^{\circ} \mathrm{W}\right)$, where there is a continuous record dating back to 1957 , there is an indication of a slight cooling over this period during autumn, but a small warming during other seasons, although none of these trends is statistically significant. The South Pole shows limited cooling in each season, although only the annual trend of $0.20{ }^{\circ} \mathrm{C}$ of cooling per decade is statistically significant at the $90 \%$ level. Data from Vostok for 1957-2000 do not show any statistically significant trend in any season or in the annual data.
Trends in the ice-skin temperature based on remote-sensing data have been examined $^{4}$ for 1979-98. The greatest cooling was found over the high plateau of east Antarctica, with some cooling over west Antarctica, but with warming over the area from the southern Weddell Sea towards the South Pole. Another study ${ }^{5}$ examined temperature trends across west Antarctica using automatic weather-station observations and satellite passive microwave measurements: the only statistically significant trend found at the $95 \%$ level was an increase of $2{ }^{\circ} \mathrm{C}$ at Siple $\left(75.9^{\circ} \mathrm{S}, 84.2^{\circ} \mathrm{W}\right)$ over the period 1979-97.

Attempting to derive a temperature trend for the entire Antarctic continent is almost meaningless, as huge areas are devoid of long-term, in situ climate measurements. At present, the trends from the various stations present a spatially complex picture of change across the continent during recent decades and do not indicate any consistent warming or cooling.

John Turner ${ }^{\star}$, John C. King*,

Tom A. Lachlan-Cope ${ }^{\star}$, Phil D. Jones $\dagger$

${ }^{\star}$ British Antarctic Survey, Natural Environment

Research Council, Cambridge CB3 OET, UK

e-mail: j.turner@bas.ac.uk

$\dagger$ Climatic Research Unit, University of East Anglia, Norwich NR4 7TJ, UK

\footnotetext{
1. Doran, P. T. et al. Nature 415, 517-520 (2002).

2. Jones, P. D., New, M., Parker, D. E., Martin, S. \& Rigor, I. G. Rev. Geophys. 37, 173-199 (1999).

3. Vaughan, D. G., Marshall, G. J., Connolley, W. M., King, J. C. \& Mulvaney, R. Science 293, 1777-1779 (2001).

4. Comiso, J. C. J. Clim. 13, 1674-1696 (2000).

5. Shuman, C. A. \& Stearns, C. R. J. Clim. 14, 1977-1988 (2001).
}

Doran et al. reply - Turner et al. do not find fault with our main focus - the rapid ecological response to recent cooling in the McMurdo Dry Valleys. The essence of their comment is that the spatial interpolation of the Antarctic continental data set (our Fig. 2) does not provide a meaningful picture of recent temperature trends. Although any interpolation is open to question, we note the following points.

First, weighting by inverse-fourth-power of separation distance in our analysis effectively eliminates contributions near to the 2,284-km radius of influence if other stations are closer. Only between the Antarctic Peninsula and the Ross Sea does the gap between points approach the radius of influence. Second, the trend maps in our Fig. 2 have features that are finer than the quarter-image radius of influence, indicating that that local data prevail in our analysis. Third, the interpolated fields are consistent with the summaries for 1976-2000 in Fig. 2.10 of the recent IPCC WG-I report ${ }^{1}$ and with trends based on a different data $\operatorname{set}^{2}$ for 1965-1999, an interval that was chosen because it was one of global warming. A recent depiction ${ }^{3}$ of combined summer and autumn Antarctic surface-temperature trends from 1969 to 2000 is similar to ours, although our data suggest that cooling is more pronounced during autumn periods than in summer.

The key question that arises is this: is our interpolation better than arithmetic averaging? We contend that, although the interpolations involve uncertainty, they highlight the fact that a full assessment of Antarctic temperature trends requires more than the averaging schemes that have so far been used to imply that Antarctica has been warming at a rate that is faster than the global average $e^{4,5}$.

In estimates of hemispheric anomalies or trends (for example, see the IPCC's Figure 2.7; ref. 1), regions that are devoid of data are effectively assigned anomalies (or trends) that are equal to the hemispheric means of anomalies (or trends) for areas for which data exist. This type of assignment ignores information from even nearestneighbour grid cells. We maintain that our approach represents an improvement over arithmetic means of station values or grid cells, provided that the nature of the interpolation procedure is clearly stated.

Only by interpolation can one hope to determine the area fraction and spatial pattern of continental warming or cooling, regardless of the magnitudes of such trends — which are irrelevant to our conclusions. As Antarctic trends obviously vary spatially, seasonally and interdecadally, interpolation will ultimately be required to optimize the information contained in historical data.

J. E. Walsh, P. T. Doran ${ }^{\star}$, J. C. Priscu,

W. B. Lyons, A. G. Fountain, D. M. McKnight, D. L. Moorhead, R. A. Virginia, D. H. Wall, G. D. Clow, C. H. Fritsen, C. P. McKay, A. N. Parsons ${ }^{\star}$ Department of Earth and Environmental Sciences, University of Illinois at Chicago,

Illinois 60607, USA

e-mail:pdoran@uic.edu

\footnotetext{
1. Houghton, J. T. et al. (eds) Climate Change 2001: The Scientific Basis (Intergovernmental Panel on Climate Change, Cambridge Univ. Press, 2001).

2. Hansen, J. et al. J. Geophys. Res. 106 (D20), 23947-23963 (2001).

3. Thompson, D. J. W. \& Solomon, S. Science 296, 895-899 (2002).

4. Jacka, T. H. \& Budd, W. F. Ann. Glaciol. 27, 553-559 (1998).

5. Vaughan, D. G., Marshall, G. J., Connolley, W. M., King, J. C. \& Mulvaney, R. Science 293, 1777-1779 (2001).
}

brief communications is intended to provide a forum for both brief, topical reports of general scientific interest and technical discussion of recently published material of particular interest to non-specialist readers. Priority will be given to contributions that have fewer than 500 words, 10 references and only one figure. Detailed guidelines are available on Nature's website (www.nature.com/nature) or on request from nature@nature.com 